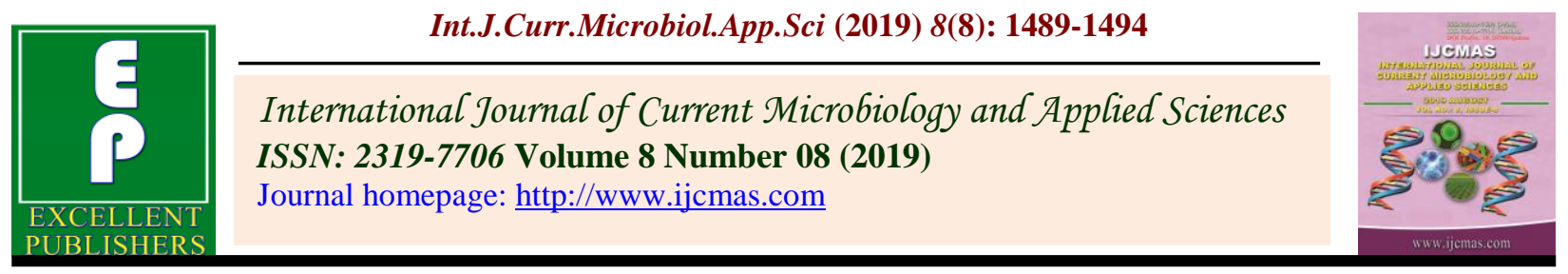

Original Research Article

https://doi.org/10.20546/ijcmas.2019.808.174

\title{
Analysis of Skin Microbiota from Canine Dermatitis in Odisha, India
}

\author{
Sudipta Jena $^{1 *}$, Rajashree Mishra ${ }^{1}$, Ritun Patra ${ }^{2}$, Debi Prasanna Das ${ }^{3}$ and S.S. Behera ${ }^{1}$ \\ ${ }^{1}$ Department of Veterinary Microbiology, College of Veterinary Science and Animal \\ Husbandry, OUAT, Bhubaneswar, India \\ ${ }^{2}$ Department of Veterinary Anatomy, College of Veterinary Science and Animal Husbandry, \\ OUAT, Bhubaneswar, India \\ ${ }^{3}$ Department of Veterinary Pathology, College of Veterinary Science and Animal Husbandry, \\ OUAT, Bhubaneswar, India \\ *Corresponding author
}

\section{A B S T R A C T}

In the present study 86 number of skin scrapings were collected from various breeds like Labrador retriever $(n=32)$, German shepherd $(n=21)$, Spitz $(n=9)$, Dacshund $(n=16)$,

\begin{tabular}{|c|}
\hline Keywords \\
\hline $\begin{array}{l}\text { Canine, } \\
\text { Dermatophytes, } \\
\text { Prevalence }\end{array}$ \\
\hline Article Info \\
\hline $\begin{array}{l}\text { Accepted: } \\
\text { 12 July } 2019 \\
\text { Available Online } \\
10 \text { August } 2019\end{array}$ \\
\hline
\end{tabular}
Mastiff $(n=5)$, Boxer $(n=3)$ and age groups from 6 months to, above 3 year with characteristics ring like lesions, alopecia, irregular patches of hair loss. All the dogs were presented to teaching veterinary clinical complex, Odisha veterinary college from December 2018 to June 2019.On routine identification of fungus out of 86 number of skin scrappings it was revealed that arthospores were present in 54 number of samples. The predominant fungal infection from the ringworm infected dog cases was found to be Microsporum species (48.15\%). Microscopic examination with cotton blue stain and wet mount method by $10 \%$ aqueous solutions of potassium hydroxide was done for identification of dermatophytes. Highest percent of infection was noticed between 6month to one and half year aged groups of canine species, may be due to poor development of immunity. Highest prevalence of dermatomycosis was recorded in Labrador retriever $(37.03 \%)$ followed by German shepherd breed $(25.92 \%)$ of canine species. On disk diffusion method of antifungal susceptibility test it was found that Miconazole $(10 \mu \mathrm{g})$ was found to be highly sensitive followed by Ketoconazole $(15 \mu \mathrm{g})$, Clotrimazole $(10 \mu \mathrm{g})$.

\section{Introduction}

Dermatophytosis is the common infectious fungal disease of canines caused by dermatophytes that are species of fungi belonging to Microsporum, Tricophyton and Epidermophyton genera (Quinn et al., 2002; Sekar et al., 2011). The disease is important from public health as well as economic point of view because it is a zoonotic skin disease causing occupational mycozoonoses of dairymen, animal handlers, pet owners, veterinarians, etc. (Ruben, 2010). Poor management of pets increases the incidence of dermatophytosis. The disease is mostly caused by Microsporum spp and at times by Trichophyton spp. In nature these genera of fungi are zoophilic and/or anthrophilic (Sharma et al., 2009; 2010). Dermatophytosis is a contagious disease of keratinized tissues 
of livestocks including dogs. The prevalence of diseases were found to be significantly positive in tropical country like India because of warm and humid climate, crowed living and poor sanitary conditions (Weese and Fulford, 2010). In higher humidity condition, faster multiplication and propagation of fungal elememts occurs (Pier et al., 1994).

Characteristics dermatophytic lesions include multifocal alopecia, mild or intense pruritis and round scaly lesions with erythematous and scaly borders (Cafarchia et al., 2004).

\section{Materials and Methods}

\section{Sample collection}

In the present study a total of 86 number of skin scrapings were collected from infected canines presented to Teaching Veterinary Clinical Complex Odisha veterinary College during the period from December 2018 to June 2019. Samples with the evidence of dermatophytosis such as ring like lesions, pruritis, irregular patches of hair loss from different breeds and ages of dogs were collected and screened for presence of various mycological agents with special reference to Microsporum species.

\section{Direct microscopic examination}

The collected materials were placed on a clean glass slide, a drop of $10 \%$ aqueous solutions of potassium hydroxide $(\mathrm{KOH})$ was added for demonstaration of fungal elements.

A cover slip was placed on the prepared slide and gently warmed over a flame, avoiding boiling. The slide was then cooled for a few minutes and excessive $\mathrm{KOH}$ solution was removed by gentle blotting for better observation of fungal hyphae, arthrospores etc.

\section{Isolation and characterization}

Isolation of fungus was done as per the methods of Nilce et al., (2008), Murmu et al., (2016). Collected samples were cultured on Sabourad's dextrose agar with $0.05 \%$ chloramphenicol and cycloheximide for primary isolation since they suppressed bacteria and saprophytic fungal growth respectively and the samples were characterized according to their colony characteristics, conidial cell structure, size, shape and presence of septae and arrangements of conidial cells around the hyphae.

\section{Inoculation of medium}

Skin scrapings were inoculated in three sets of test tubes-one containing Sabourad's dextrose agar with $0.05 \%$ chloramphenicol, second containing Sabourad's dextrose agar with $0.05 \%$ chloramphenicol plus $0.05 \%$ cycloheximide and third one into dermatophyte test medium and incubated the first two sets for up to 4 weeks at $28{ }^{\circ} \mathrm{C}$ and the last set for up to 10 days and periodical examination was done for any growth or colour change.

\section{Identification}

Identification of the positive samples were done following 'Dermatophyte identification scheme' as per Koneman and Roberts (1985) Sekar and Dogan (2011). Colony morphology and microscopic examination was carried by lactophenol cotton blue stain. Other tests such as urease test, in-vitro hair perforation test were carried out to confirm the presence of different isolates.

\section{Antifungal susceptibility test}

Muller Hinton Agar (MHA) obtained from M/S Hi-Media Laboratories Ltd. Mumbai with 
2\% glucose was employed for the in-vitro antifungal sensitivity test of dermatophytes isolates as per the commonly used disc diffusion method Bauer et al., (1966).

The antifungal discs used are Ketoconazole $(15 \mu \mathrm{g})$, Miconazole $(10 \mu \mathrm{g})$, Fluconazole $(25 \mu \mathrm{g})$, Clotrimazole $(10 \mu \mathrm{g})$ and the zone of inhibition was recorded after incubation at $28^{\circ} \mathrm{C}$ for 5-10 days.

\section{Results and Discussion}

In the present study, 86 no of breeds consisting of Labrador retriever, German shepherd, Dacshund, Mastiff, Boxer, Spitz with a history of alopecia (Fig. 1b), erythema, characteristics ring like lesions (1a, 1d), Scaly patches (1c) were examined, after isolation and thorough characterization, a total of 54 (62.79\%) samples were found to be positive for mycotic infection. The predominant isolates from the ringworm infected dog cases was Microsporum spp (48.15\%). Fungal macro and micro morphology was carried out in potato dextrose agar and Sabourad's dextrose agar.

The colonies of Microsporum spp. were wooly aerial mycelia (Fig. 3). The microscopical study revealed the presence of well-developed macroconidia with septa and small microconidia with stalked appearance (Fig. 2).

Out of six breeds of canine species screened for fungal infection, it was observed that highest occurance was in Labrador retriver $(37.03 \%)$ followed by Germansepherd (25.92\%), Dacshund (24.07\%), Spitz (9.26\%), Mastiff $(1.86 \%)$ and Boxer $(1.86 \%)$. The breed wise prevalence of canine dermatomycosis was depicted in Table 1 . The highest prevalence in Labrador retriever followed by German shepherd might be due to long hair of animals. Higher humidity is congenial for faster multiplication and propagation of fungal elements as per Bhardwaj et al., (2012), Pier et al., (1994).

Table.1 (Breed wise occurance of dermatomycosis in canine species)

\begin{tabular}{|l|c|c|c|}
\hline Breed & Total no of cases & $\begin{array}{c}\text { No of cases positive for } \\
\text { arthrospores }\end{array}$ & $\begin{array}{c}\text { Percent from total no of } \\
\text { positive cases }(\mathbf{n}=\mathbf{5 4})\end{array}$ \\
\hline Labrador retriever & 32 & 20 & 37.03 \\
\hline Dacshund & 16 & 13 & 24.07 \\
\hline German shepherd & 21 & 14 & 25.92 \\
\hline Spitz & 9 & 5 & 9.26 \\
\hline Mastiff & 5 & 1 & 1.86 \\
\hline Boxer & 3 & 1 & 1.86 \\
\hline Total & 86 & 54 & 100.00 \\
\hline
\end{tabular}

Table.2 (Age wise occurrence of dermatomycosis in canine species)

\begin{tabular}{|l|c|c|c|c|}
\hline $\begin{array}{l}\text { Age group of } \\
\text { canine species }\end{array}$ & $\begin{array}{c}\text { No of cases positive for } \\
\text { arthrospores }(\mathbf{n = 5 4})\end{array}$ & $\begin{array}{c}\text { Percent from total } \\
\text { no of positive cases }\end{array}$ & $\begin{array}{c}\text { Microsporom } \\
\text { spp. (\%) }\end{array}$ & $\begin{array}{c}\text { Trichophyton } \\
\text { spp. (\%) }\end{array}$ \\
\hline $\mathbf{6 - 1 8}$ months & 25 & 46.3 & 25.93 & 5.6 \\
\hline $\mathbf{1 . 5 - 3}$ yr & 18 & 33.33 & 14.81 & 3.7 \\
\hline Above 3 yr & 11 & 20.37 & 7.40 & 1.8 \\
\hline Total & 54 & 100 & 48.14 & 11.1 \\
\hline
\end{tabular}


Fig.1a Ringworm infection in Labrador retriever breed of canine species

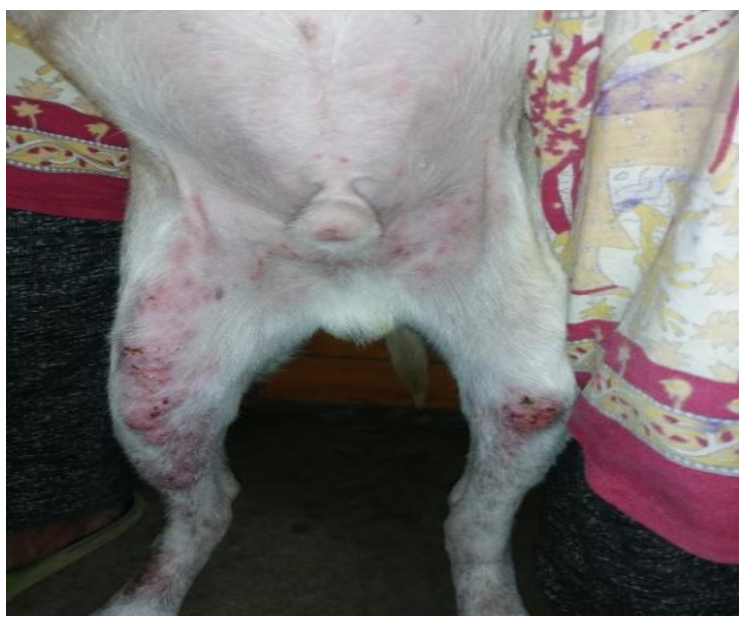

Fig.1b Alopecia in German shepherd breed of canine species

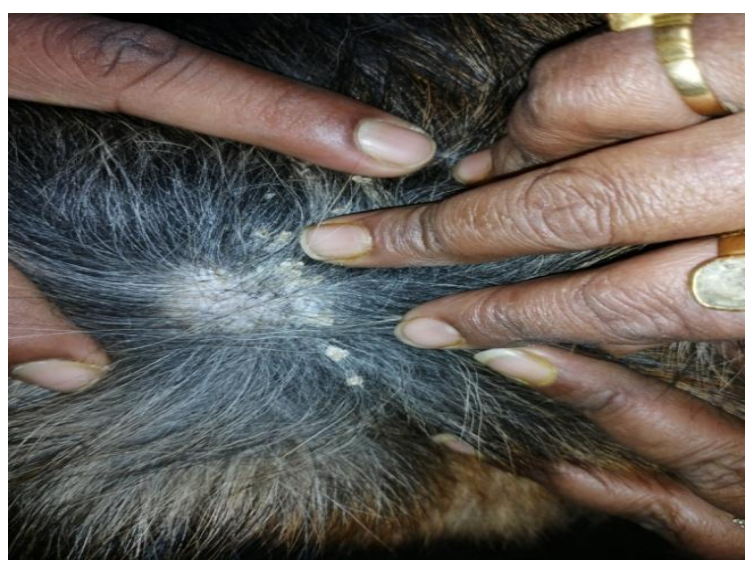

Fig.1c Scaly patches in Spitz breed of canine species

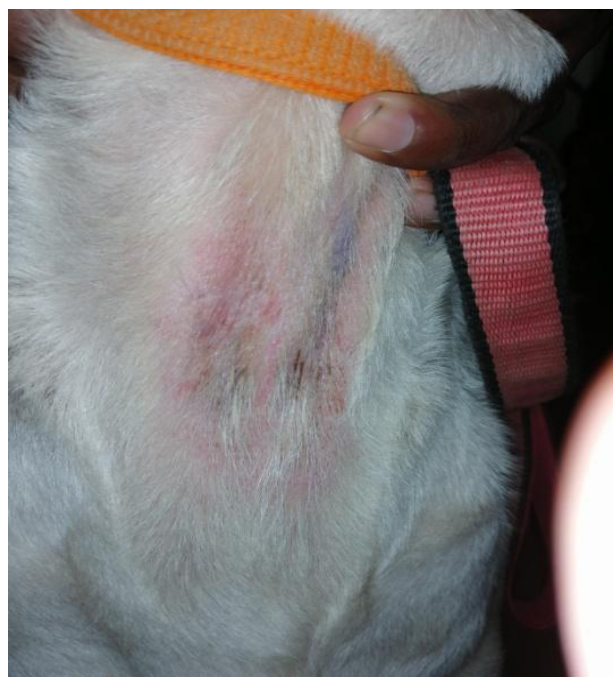


Fig.1d Ring worm infection in German shepherd breed of canine species

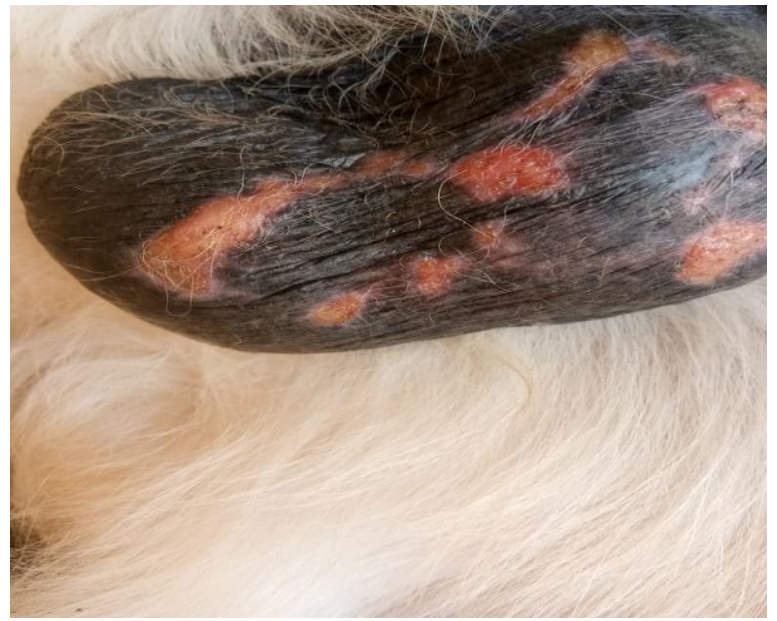

Fig.2 Microsporum spp. in Labrador retriever breed of canine species (Lactophenol cotton blue stain)

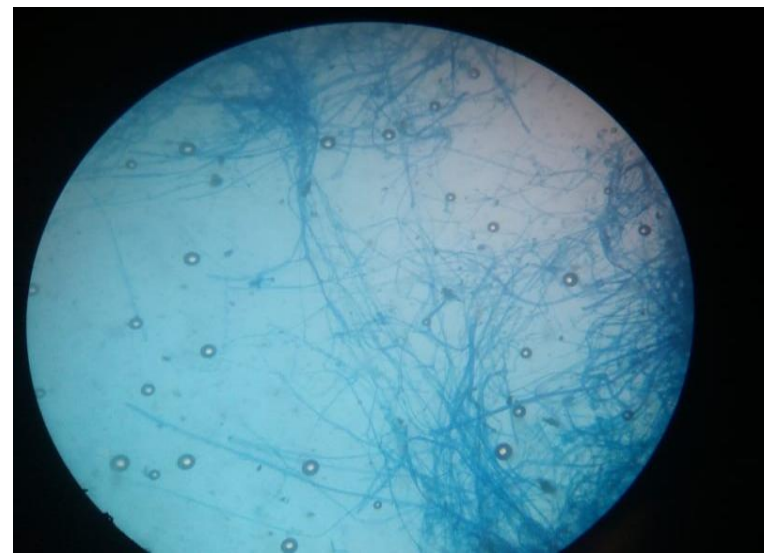

Fig.3 Growth of Microsporum species (cottony to wooly appearing colony) in Sabourad's dextrose agar slant

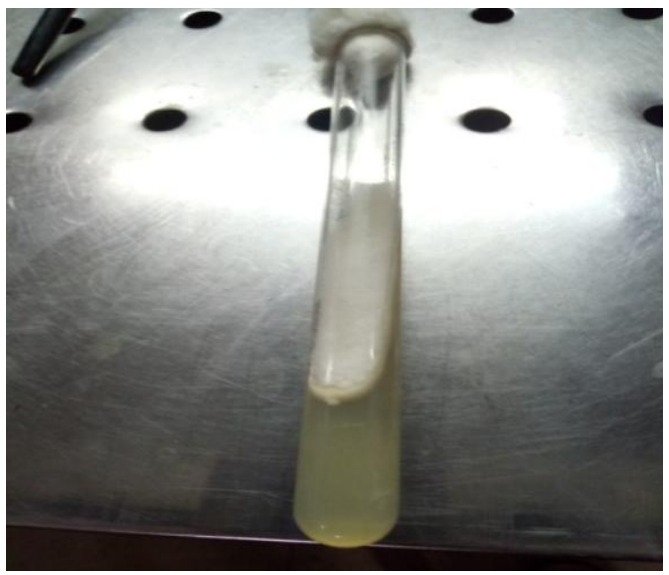


It was found by tooth brush culture of skin scrapping that the younger dog population aged between 6month to 1.5 year was comparatively more susceptible to dermatomycotic infection with a higher rate of occurrence $(46.3 \%)$ than that of above one and half year old $(33.33 \%)$ and further it was observed higher age group of over three years of canine species the rate of incidence of ringworm was $20.37 \%$. Result of age wise occurrence of dermatomycosis of dogs was given in Table 2.

On disk diffusion method of antifungal susceptibility test it was found that Miconazole $(10 \mu \mathrm{g})$ was found to be highly sensitive followed by Ketoconazole $(15 \mu \mathrm{g})$, Clotrimazole $(10 \mu \mathrm{g})$ against dermatophytes.

Due to zoonotic nature of ringworm infection in dogs further molecular study on other contaminated objects will reveal a correlation for transmission of dermatophytes infection.

\section{References}

Bhardwaj RK, Taku AK and Ahmad I (2012) Therapeutic management of dermatophytosis in canine. Indian Vet. J. 89: 61-62.

Cafarchia C, Romito D, Sasaneli M, Lia R, Capelli G and Otranto D. (2004) The epidemiology of canine and feline dermatophytoses in Southern Italy, Mycoses 47:508-513.

Koneman EW and Roberts GD. (1985) Dermatophyte identification schema. In; Practical Laboratory Mycology, $3^{\text {rd }}$ ed. Williams \& Wikins, Baltimore.
Murmu S, Debnath C, Pramanik AK, Mitra T, Jana S, Banerjee S, Isore DP and Batabyal K. (2016) Characterization and anti-fungal susceptibility pattern of dermatophytes isolated from dogs, cats and pet owners in and around Kolkata, India, Indian J. Anim. Res. B-3040: 1-4.

Nilce M, Martinez R and Nulu TA. (2008) Antifungal resistance mechanism in dermatophytes, Mycopathologia. 166: 369-383.

Pier AC, Smith JMB, Alexiou H, Ellis DH, Lund A and Prichard RC (1994) Animal ringworm -its etiology public health significance and control, J. Med. Vet. Mycol. 32: 133-150.

Quinn PJ, Markey BK, Carter ME, Donnelly WJ and Leonard FC. (2002) Veterinary Microbiology and Microbial Disease. Blackwell Publishing Professional, lowa.

Ruben LM. (2010) Candidosis, a new challenge, Clin. Dermatol. 28: 178-184

Seker E and Dogan N. (2011) Isolation of dermatophytes from dogs and cats with suspected dermatophytosis in Western Turkey, Preventive Veterinary Medicine. 98: 46-51.

Sharma DK, Joshi G, Lakhotia RL and Sharma K. (2010) Canine dermatophytosis, Indian Vet. J. 87: 610611.

Sharma DK, Joshi G, Singathia R and Lakhotia RL. (2009) Zooantroponosis of Microsporum gypseum infection, Haryana Vet 48: 108-109.

Weese JS and Fulford M. (2010) Companion Animal Zoonoses, Wiley-Blackwell, New Jersey. 278-279.

\section{How to cite this article:}

Sudipta Jena, Rajashree Mishra, Ritun Patra, Debi Prasanna Das and Behera, S.S. 2019. Analysis of Skin Microbiota from Canine Dermatitis in Odisha, India. Int.J.Curr.Microbiol.App.Sci. 8(08): 1489-1494. doi: https://doi.org/10.20546/ijcmas.2019.808.174 